\title{
Traits of Menstrual Problems in Rural Adolescent Eves
}

\author{
Rajiv Mahendru ${ }^{1}$, Vijayata ${ }^{1}$, Sunita Siwach ${ }^{1}$, Pinkey Lakra ${ }^{1}$, Shivani $^{1}$, Saloni Bansal ${ }^{2}$ and Mani Mehrotra ${ }^{3}$ \\ ${ }^{1}$ Deptt of Obstetrics and Gynaecology, BPS Govt Medical College for Women, India \\ ${ }^{2}$ Consultant Gynaecologist, AMCMH, India \\ ${ }^{3}$ Consultant Gynaecologist, $\mathrm{CH}$, India
}

Submission: August 21, 2018; Published: September 07, 2018

*Corresponding author: Rajiv Mahendru, Professor and Head, Deptt of Obstetrics and Gynaecology, BPS Govt Medical College for Women, Khanpur Kalan (Sonepat), Haryana, India, Tel: +91 9416086483; Email: dr.rmahendru@gmail.com

Summary

Introduction: Adolescence is a time of enormous physical and psychological change for young women in which there is probability of menstrual problems adding to the already difficult phase.

Objective: To study the menstrual characteristics of rural adolescents.

Methods: Subjects were the ones who presented to the medical college with some menstrual complaints. A self administered Questionnaire based on the age, menarche, menstrual characteristics, menstrual problems, hygiene was used for data collection.

Results: Most common problem was menorrhagia as reported by $71.3 \%$ respondents, dysmenorrhoea was an accompaniment in $29 \%$ of the subjects. The mean cycle length was 31.2 days; mean cycle duration 5.7 days. About one-third of the girls had irregular cycles at the onset.

Conclusions: Menorrhagia was the main presenting complaint and dysmenorrhoea was an accompaniment in only a few. The need for proper knowledge, guidance and counselling is emphasised.

Keywords: Menorrhagia; Dysmenorrhoea; Adolescent

\section{Introduction}

The word adolescent is derived from the Latin word, adolescere meaning "growing to maturity". Adolescence is a time of enormous physical and psychological change for young women. Pathologies of serious nature are rare in this age group, but menstrual problems do occur and add on to the already difficult phase of adolescence. Puberty is recognized as a special period that signifies the transition of girlhood to womanhood. It is marked with the onset of menarche, an important milestone. Experience of first menstrual bleeding during puberty is defined as menarche. WHO defines this phase from 10-19 years of age [1]. Onset of menstruation is due to the activation of hypothalamic-pituitary-ovarian axis. Gonadotropins of the anterior pituitary i.e. follicle stimulating hormone (FSH) and luteinizing hormone ( $\mathrm{LH})$ under the control of hypothalamic hormones (gonadotropins-releasing hormone) act on the ovaries to release oestrogen and progesterone which further act on the endometrium of the uterus to cause its proliferation and shedding in a cyclical manner [2]. This phase is affected by various physiological, pathological and psychological changes. Adolescents may have difficulty raising issues on menstruation, hence require particular skills and sensitivities. Recently
ACOG and RCOG have also approved a special training module in Paediatric and Adolescent Gynaecology [3]. Menarche and sexual health education go hand-in-hand. Henceforth, effective prevention strategies must centre the adolescent population.

\section{Materials and Methods}

This is a prospective study of menstrual characteristics of rural adolescents conducted in the medical college situated in the rural area of Haryana for a period of one year and approved by the departmental ethical committee. Subjects were the ones who presented to the medical college with some menstrual complaints. The study was chosen as tender adolescents have shyness and difficulty discussing menstrual problems and may present only the minor complaints rather than the primary concerns. Thus the guidance and information to them may help ease this transition from childhood through puberty and a healthy adolescence. Place of study was chosen to be medical college as the availability of staff was adequate and in future interventional programmes could be executed if required. The study was initiated after departmental ethical clearance and stratified random sampling was the technique. After obtaining 
the informed consent of the girl and the guardian, social worker gave the brief information about the study, its importance and relevance. Reassurance was given for not revealing the personal identity. A self administered Questionnaire was used for data collection. Questionnaire was discussed in the department before finalization. It had questions on the age, menarche, menstrual characteristics, menstrual problems, hygiene and source of information. Identity was concealed in the Questionnaires. Questionnaires were distributed and collected at the same time to avoid bias. Statistical analysis was done using simple percentage test.

\section{Results}

Out of the 700 Questionnaires distributed 678 were completely filled and returned. These were included in the final analysis and rest discarded (either not filled completely or blank). The age of the respondents were between 13-18 years as shown in Table 1 , mean being $15 \pm 0.87$ years.

Table 1: Age distribution of respondents.

\begin{tabular}{|c|c|c|}
\hline Age in Years & Frequency & Percentage (\%) \\
\hline $13-14$ & 167 & 24.6 \\
\hline $14-15$ & 111 & 16.4 \\
\hline $15-16$ & 201 & 29.6 \\
\hline $16-17$ & 97 & 14.3 \\
\hline $17-18$ & 102 & 15.1 \\
\hline
\end{tabular}

Menstrual characteristics, mean cycle length was 31.2 days; mean cycle duration 5.7 days. About one-third of the girls had irregular cycles at the onset. By about 3 years $90 \%$ had regular cycles while $10 \%$ still had irregular cycles. The frequency distribution of cycle length and duration is seen in Table $2 \& 3$, respectively.

Table 2: Duration of menstrual cycle of respondents.

\begin{tabular}{|c|c|c|}
\hline Cycle Length in Days & Frequency & Percentage (\%) \\
\hline $21-28$ & 91 & 13.4 \\
\hline $28-35$ & 392 & 57.8 \\
\hline $35-45$ & 107 & 15.8 \\
\hline $45-60$ & 88 & 13 \\
\hline
\end{tabular}

Table 3: Duration of menstrual cycle of respondents.

\begin{tabular}{|c|c|c|}
\hline Duration & Frequency & Percentage (\%) \\
\hline$>2$ & 0 & 0 \\
\hline 2 & 19 & 2.8 \\
\hline 3 & 149 & 22 \\
\hline 4 & 118 & 17.4 \\
\hline 5 & 219 & 32.3 \\
\hline 6 & 99 & 14.6 \\
\hline 7 & 74 & 10.9 \\
\hline
\end{tabular}

Most common problem was menorrhagia as reported by $71.3 \%$ respondents, dysmenorrhoea was an accompaniment in $29 \%$ of the subjects, menometrorhagia in $17.7 \%$ and oligomenorrhoea in $11 \%$. Out of the total patients presenting with menorrhagia, only $2.1 \%$ reported at the first episode. Dysmenorrhoea was never a presenting complaint. Sixty percent were unaware of hygiene during flow. Majority of these girls used fresh old plain cloth (84.3\%) and only 11 percent were using commercially available sanitary napkins, rest reused the cotton clothes. Sixty-seven percent of the eves were not aware of the safe sex. There were 3 recorded adolescent pregnancies during the study period. Information on this topic (menstruation and sex education) was incomplete and major source of information were the parents (mother or elder sister) in 78.6\%; inputs from teachers $(14 \%)$ and health care providers $(7.4 \%)$ was lacking.

\section{Discussion}

Age of menarche depends on multiple physiological, psychological and pathological factors. States of chronic diseases, malnutrition and eating disorders tend to delay menarche, whereas obesity on the other hand leads to early menarche. Hormones like insulin and leptin have a role to play by regulating insulin-like growth factor binding protein and sex hormone binding globulin3. In various studies conducted on adolescent girls in rural India, observations on age at menarche were similar to the present study. Joseph et al [4] quoted it to be 13.9 years, Nair et al. [5] 13.6 years and Sachan et al. [6] 13.19 years, these all were found to be almost similar to that found in our study i.e 13.1 years. A trend towards early menarche as observed by Singh A et al. [7] (12.5 years) was not seen in the present study as adolescents in this rural area are still uninformed, poorly educated and in states of malnutrition.

Mean cycle length was 31.2 days, with $57.8 \%$ of respondents ranged from 28-35 days. Similarly the mean duration of flow was 5.7 days, maximum of 7 days duration but most commonly, as many as $32.3 \%$ reported it to be 5 days. The above menstrual characteristics of these adolescent eves are consistent with those described by Sachan [6] and Gumanga [2].

Whilst adolescent menstrual cycles may initially be variable, as seen here about one-third of the girls had irregular cycles at the onset, agreeing to the findings of Sachan [6] and Agarwal [8]. Anovulation does not necessarily underlie irregularity while some may be ovulatory with long follicular phase [3]. By about 3 years $90 \%$ had regular cycles while $10 \%$ still had irregular cycles.

What was found to be alarming here was, menorrhagia as the most common presenting complaint, reported by $71.3 \%$ of girls. This is in strict contrast to the findings of Sharad [9] and Verma [10] who reported it to be $14 \%$ and $8.7 \%$ respectively. Probably the reason for this is that the present research was carried out on the subjects who reported to the institute with one or the other menstrual complaints, whereas previous ones were carried out on masses. Further poor understanding of what constitutes a normal menstruation led to late reporting as only $2.1 \%$ reported it at the first episode. 
Another contradictory finding was the low incidence of dysmenorrhoea in the study population. It was an accompaniment in only $29 \%$ of girls whereas the earlier series had reported an incidence as high as $50.6 \%$ by Verma et al. [10]; $73.83 \%$ by Singh A et al. [7] and 75\% by Sachan et al. [6]. It is a perceptive symptom and depends upon pain threshold and social environment you are brought up in. Dysmenorrhoea is possibly less here due to poor literacy level on the part of the mother, cultural taboos and lack of knowledge on menstruation.

Information on menstruation and safe sex was little and major source of information were the parents (mother or elder sister) in 78.6\%; inputs from teachers (14\%) and health care providers $(7.4 \%)$ was lacking. Even there were three reported adolescent pregnancies. Accurate education from the right source is important as misconceptions do exist. Even the study of Gumanga [2] from Ghana had similar findings of less than $10 \%$ contribution from health providers while for over $80 \%$ the source were the parents. It is unwise and impossible to separate menarche from sexual health education. Guidance about contraception and sexually transmitted infections is important. Early menarche is associated with earlier onset of sexual debut and hence problems of teenage pregnancies and unsafe abortions. Education should thus be imparted at school, college and community level.

Hygiene was another issue that needs to be taken care of. Still only 11 percent were using commercially available sanitary napkins rest used cotton clothes. Likely the prolonged menstruation was one of the contributory factors apart from shyness, hesitation and may be the economic status. Verma et al. [10] also found usage of sanitary pads by only $10.6 \%$.

\section{Conclusion}

Inspite of a trend towards early menarchenowadays, it was not seen in the present study. Menorrhagia was the main presenting complaint and dysmenorrhoea was an accompaniment in only a few. The need for proper knowledge, guidance and counselling is unmet. Health care professionals have a greater role to play in accurately educating the adolescents on menstruation, teaching them hygiene and safe sexual practices. Menstruation management should be included in the curriculum. Health providers need to compliment the current efforts made by parents to smoothen the transition of girlhood to womenhood.

\section{Limitation}

Present study targeted only the girls visiting the hospital while there may be many more in the community hiding due to hesitation. So should be extended at community level.

\section{References}

1. Waghachavare VB, Chavan VM, Dhumale GB (2013) A study of menstrual problems among the female junior college students from rural area of Sangli District. National Journal of Community Medicine 4(2): 236-240.

2. Gumanga SK, Kwame-Aryee RA (2012) Menstrual characteristics in some adolescent girls in Accra, Ghana. Ghana Medical Journal 46(1): 3-7.

3. Hickey M, Balen A (2003) Menstrual disorders in adolescence: investigation and Management. Human Reproduction Update 9(5): 493-504.

4. Joseph GA, Bhattacharji S, Joseph A, Rao PS (1997) General and Reproductive Health of Adolescent Girls in Rural South India. Indian Pediatr 34(3): 242-245.

5. Nair P, Grover VL, Kannan AT (2007) Awareness and practices of menstruation and pubertal changes amongst unmarried female adolescents in a rural area of East Delhi. Indian J Com Med 32(2): 156157.

6. Sachan B, Idris MZ, Jain S, Kumari R, Singh A, et al. (2012) Age at Menarche and Menstrual Problems Among School-Going Adolescent Girls of a North Indian District. Journal of Basic and Clinical Reproductive Sciences 1(1,2): 56-59.

7. Singh A, Kiran D, Singh H, Nel B, Singh P, et al. (2008) Prevalence and severity of dysmenorrhea: a problem related to menstruation, among first and second year female medical students. Indian J Physiol Pharmacol 52(4): 389-397.

8. Agarwal A, Agarwal AK (2008) A Study of Dysmenorrhea among Adolescent Girls (15-20 years). Indian J Prev Soc Med 39: 45-48.

9. Pandit SB (2014) Common Menstrual Problems among Adolescent students. Sinhgad e Journal of Nursing 4(I): 45-47.

10. Verma PB, Pandya CM, Ramanuj VA, Singh MP (2011) Menstrual Pattern of Adolescent School Girls of Bhavnagar (Gujarat). NJIRM 2(1): 38-40.

\begin{tabular}{|l|}
\hline \multicolumn{1}{|c|}{ Your next submission with Juniper Publishers } \\
will reach you the below assets \\
- Quality Editorial service \\
- Swift Peer Review \\
- Reprints availability \\
- E-prints Service \\
- Manuscript Podcast for convenient understanding \\
- Global attainment for your research \\
- Manuscript accessibility in different formats \\
( Pdf, E-pub, Full Text, Audio) \\
- Unceasing customer service \\
Track the below URL for one-step submission \\
https://juniperpublishers.com/online-submission.php \\
\hline
\end{tabular}

